Available online on 15.01.2020 at http://jddtonline.info
Open Access to Pharmaceutical and Medical Research
unrestricted non-commercial use, provided the original work is properly cited

Open@ Access

Research Article

\title{
Bisphenol-A in Wistar Rats: Toxicological Study as Mitochondrial Disrupting Agent
}

\author{
Ahmad Zahak* and Rohit Saraswat \\ School of Pharmacy, OPJS University, Churu, Rajasthan (India)
}

\begin{abstract}
BPA is an EDC which is continuously released into the environment because of its extensive usage as plasticizer and other industrial applications. The present study establishes BPA induced alterations in mitochondrial marker enzymes and hence cause mitocho ndrial dysfunction. Studies were performed to evaluate the histopathological changes in tissue on exposure to different doses of BPA for different time periods. Light microscopic examination of samples was done to evaluate the possible changes caused by treatment of different doses of BPA. After getting the results in light microscopy the changes and damage caused by BPA ultra-structurally were observed. Light microscopic study showed that BPA exposure for short duration of 7 days did not resulted in significant change in histology of Rat of treated a nimals. Light microscopic observations showed that low doses of BPA ( 5 and $10 \mathrm{mg} / \mathrm{kg}$ body weight) exposure for 14 days caused reduction in the number of cells in the layers of seminiferous tubules. Highest dose of BPA treatment for 14 days caused much damage to the seminiferous tubules. There were many ultra-structural changes found in the treated groups as compared to the control group. Hence it can be stated that due to the toxic effect of BPA the mitochondrial marker enzymes have shown marked reduction in their activities.
\end{abstract}

Keywords: BPA, EDCs, Light microscopic, Mitochondria and Toxicity.

Article Info: Received 18 Nov 2019; $\quad$ Review Completed 26 Dec 2019; $\quad$ Accepted 31 Dec 2019; Available online 15 Jan 2020

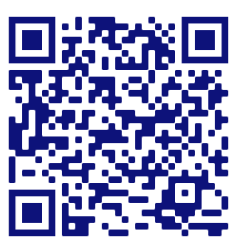

Cite this article as:

Zahak A, Saraswat R, Bisphenol-A in Wistar Rats: Toxicological Study as Mitochondrial Disrupting Agent, Journal of Drug Delivery and Therapeutics. 2020; 10(1):81-91 http://dx.doi.org/10.22270/jddt.v10i1.3849

*Address for Correspondence:

Ahmad Zahak, School of Pharmacy, OPJS University, Churu, Rajasthan (India)

\section{INTRODUCTION}

BPA is an industrial chemical used to make a hard, clear plastic known as polycarbonate, which has been used in many consumer products, including reusable water bottles. $\mathrm{BPA}$ is also found in epoxy resins, which act as a protective lining on the inside of metal-based food and beverage cans.

BPA and phosgene react to give polycarbonate under biphasic conditions; the hydrochloric acid is scavenged with aqueous base. It takes approximately one pound of BPA and one half pound of phosgene to produce one pound of polycarbonate. The polymer chains are built by alternately connecting BPA molecules and the carbon monoxide portion of the phosgene molecule as observed instead of direct phosgenation. Besides BPA and phosgene, there is another type of compound that goes into the building of the polycarbonate chain called chain terminator. Chain terminator is added to cap the ends of the chains, limiting how long they can grow (Sajiki and Yonekubo, 2004).<smiles>CC(C)(c1ccc(O)cc1)c1ccc(O)cc1</smiles><smiles>O=C(Cl)Cl</smiles><smiles>CC(Cl)C(=O)Oc1ccc(C(C)(C)c2ccc(OC(C)(C)C)cc2)cc1</smiles>

Figure 1: Formation of polycarbonate.

Polycarbonate is a commercial polymer that was discovered and developed by Dr. H. Schnell at Bayer Germany in 1953. This polymer resin known as plastic had shown many ISSN: 2250-1177 versatile and key properties for many industrial applications. Some of the properties include transparency, breakage resistance, thermal stability, flame retardance, 
electrical insulation, low density, recyclability and easy process ability. Some of the applications are electrical (38 $\%)$, lightweight glazing (20\%), compact discs (13\%), automotive $(10 \%)$, packaging $(3 \%)$, medicine $(3 \%)$, spectacles (1\%), optical lenses, material science applications and other products $(12 \%)$.

Polycarbonate plastic, which is clear and nearly shatterproof, is used to make a variety of common products including baby and water bottles, sports equipment, medical and dental devices, dental fillings and sealants, CDs, DVDs and household electronics. BPA is also used in the synthesis of polysulfones and polyether ketones, as an antioxidant in some plasticizers and as a polymerization inhibitor in PVC. Epoxy resins containing bisphenol $\mathrm{A}$ are used as coatings on the inside of almost all food and beverage cans.

BPA exposure is associated with a number of delirious health effects such as reproductive toxicity, increase in the amount of cancers in the hematopoietic system in rodents, altered cellular development, impaired neurological and behavioral development, adverse effects on immune system. BPA cause toxicity in multiple organ systems such as liver, kidney, spleen and pancreas. Antioxidant genes levels were decreased significantly in BPA treated animals. It also causes degeneration of renal tubules in kidney of rats and mice (Miao et al., 2009). BPA causes DNA strand breaks in spleen, kidney, lung and germ cells. It alters pancreatic $\beta$-cell function and can be considered a risk factor for type 2 diabetes in rodents. BPA affects not only the receptors but also other cellular components such as plasma membrane and causes membrane disruption and the functioning of endoplasmic reticulum by causing inhibition of protein disulfide isomerase reductase activity. In chromosomes it causes induction of micronuclei (Dobrzynska et al., 2010). Estrogenic compounds cause endocrine disruption by various mechanisms discussed above and also play important role in mitochondrial dysfunction.

The major human exposure route to BPA is diet, including ingestion of contaminated food and water. Bisphenol A has been known to be leached from the plastic lining of canned foods and polycarbonate plastics, especially those cleaned with harsh detergents or that contain acidic or hightemperature liquids. BPA is an ingredient in the internal coating of metal food and beverage cans used to protect the food from direct contact with the can. This included fresh turkey, canned green beans, and canned infant formula (Schecter, 2010). While most human exposure is through diet, exposure can also occur through air and through skin absorption. Free BPA is found in high concentration in thermal paper and carbonless copy paper, which would be expected to be more available for exposure than BPA bound into resin or plastic. Popular uses of thermal paper include receipts, event and cinema tickets, labels, and airline tickets. Also, other paper products, such as toilet paper, newspapers and napkins, become contaminated with BPA during the recycling process (Liao, 2011).

\section{Toxicity studies}

Exposure to high doses of BPA causes toxicity in multiple organ systems such as the kidney, liver, spleen and pancreas. High BPA doses also cause reproductive toxicity and affect cellular development in rats and mice (Morrissey et al., 1987). BPA binds to estrogen receptors and activates them (Krishnan et al., 1993). High concentrations of BPA also induce growth and prolactin secretion of estrogenresponsive pituitary tumor cell lines (Chun and Gorski, 2000). As BPA is used in many consumer products, it can enter the human body from e.g. reusable baby bottles, food packaging materials (Krishnan et al., 1993), liquid of canned

ISSN: 2250-1177 vegetables and dental sealants (Brotons et al., 1995). The entry route of BPA into the organism is, however, of importance. The absolute oral bioavailability of BPA in rats in low (about $5 \%$ ) compared to sc administration (Yoo et al., 2001).

\section{Mechanism of Bisphenol-A toxicity}

Many of the physiological effects of BPA have been described in the context of its ability to interact with classic ERs (nuclear hormone receptor activity). In addition to nuclear hormone receptor activity, BPA also has an impact on cellular physiology through rapid signaling mechanisms to modify the activities of various intracellular signaling networks. The rapid signaling effects of BPA are independent of nuclear hormone receptor activity and occur within minutes or seconds of exposure, initiated by membrane-associated or intracellular receptor systems. It is considered likely that rapid estrogen-like signaling effects and classical nuclear hormone activity interact to have a coordinated impact on physiological responses to estrogenic compounds (Wetherill et al., 2007).

Bisphenol A causes oxidative stress by the release of reactive oxygen species and free radical generation. The toxicity of BPA is manifested by lipid peroxidation and generation of free radicals causing oxidative stress. The targets of the toxic effects of BPA are probably mitochondria and mitochondrial respiration. ROS formation by mitochondria, excessive mitochondrial oxidative damage and reduced mitochondria biogenesis contribute to mitochondria disruption (Nakagawa and Tayama, 2000).

\section{EDC causing mitochondrial toxicities}

Mitochondria are targets of several environmental toxicants including environmental estrogens. For example, tertiary butyl hydro peroxide ( $t$-BHP) exposure to isolated hepatocytes caused oxidative stress and apoptosis by the involvement of caspases. $\mathrm{CdCl}_{2}, \mathrm{HgCl}_{2}$ and rotenone caused reduced mitochondrial membrane potential and increased superoxide production in both BE(2)-C and HepG2 cells. A slight mitochondrial dysfunction may affect vital functions of testes including sperm production (Monroe and Halvorsen, 2009).

Warming the plastic, such as in a microwave, increases the leaching of BPA into liquids; temperature appears to be a more important factor in leaching than the age of the container. The U.S. EPA has established the safe daily intake of BPA to be $50 \mu \mathrm{g} / \mathrm{kg}$ body weight/day based on the assumption that the main source of exposure is oral through food ingestion. However, recent publications suggest that food is not the only relevant source of exposure and that the half-life of BPA in humans is longer than expected. This practice was based on one hand on the fact that the fetus is exposed to BPA through the internal milieu of the mother, and on the other hand that parenteral administration via an osmotic minimum allows for a precise and constant level of exposure. Using this route of administration, exposure of a pregnant mouse dam to 25 and $250 \mathrm{ng}$ BPA/kg body weight/d (namely, 2000 and 200 times lower than the safe dose) for $14 \mathrm{~d}$ beginning on $\mathrm{d} 8$ gestation has been shown to impact certain aspects of development in their female offspring. When examined on gestational d 18, fetuses of mothers exposed to the higher dose of BPA exhibited altered growth parameters of the mammary gland anlagen.

\section{Properties and Uses}

BPA (CAS number 80-05-7) is a synthetic chemical that, because of its structure, has many uses. The bisphenol A (4, 4'-dihydroxy-2, 2-diphenylpropane) (BPA) molecule 
comprises two phenol rings connected by a methyl bridge, with two methyl groups attached to the bridge (Figure 3).

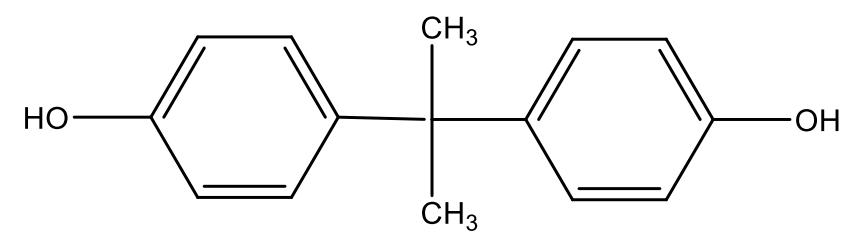

Figure 3: Bisphenol-A Chemical Structure

Most domestically produced BPA is used as an intermediate in the production of polycarbonate and epoxy resins, flame retardants and other specialty products. Final products include powder paints, adhesives, protective coatings, automotive lenses, protective window glazing, building materials, compact disks, optical lenses, thermal paper, paper coatings, as a developer in dyes and for encapsulation of electrical and electronic parts. BPA is also used in some polymers used in dental sealants or composites. BPA can migrate into foods from cans and from polycarbonate plastic products such as baby bottles, tableware, and food containers. The use of BPA in food and beverage containers accounts for the majority of daily human exposure; estimated human consumption of BPA from epoxy-lined food cans alone was $6.6 \mu \mathrm{g} /$ person-day.

\section{Endocrine Disrupting Chemicals (EDCs)}

EDC are a structurally diverse class of synthetic and natural compounds. EDCs include a variety of both natural compounds like phytoestrogens as well as man-made substances including pharmaceuticals and pesticides such as prochloraz and tebuconazole as well as a number of industrial chemicals such as polychlorinated biphenyls, and phthalates. Because EDCs consist of so many diverse compounds from many different sources, an exact level of EDC exposure is hard to give. EDCs act through a variety of receptor-mediated and non-receptor-mediated mechanisms to modulate different components of the endocrine system. Receptor-mediated mechanisms have received the most attention. EDCs are typically identified as agonists or antagonists of endogenous hormone receptors. However, EDCs can act through multiple mechanisms of action such as hormone synthesis, transport, and metabolism. Concerns regarding exposure to EDCs have primarily been related to adverse effects observed in wildlife. However, increased incidences of malformations of the reproductive organs in newborn boys, early onset of puberty, as well as increased incidence of certain endocrine-related human diseases are also generating concern (IPCS. 2002).

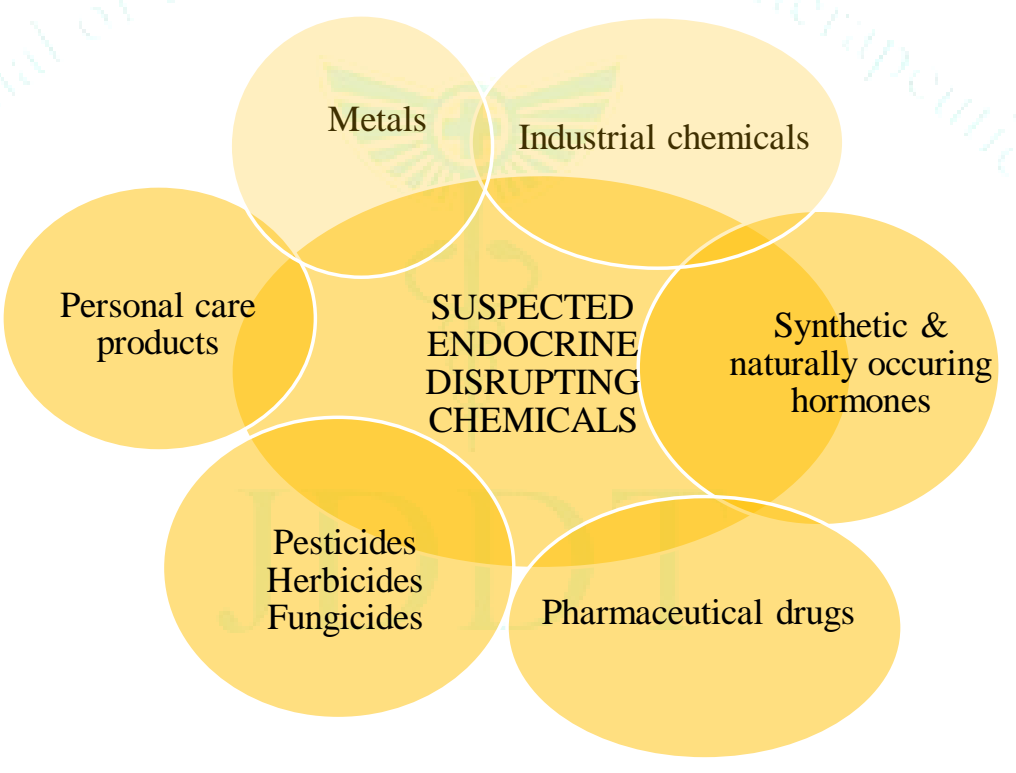

Figure 4: Different categories of suspected EDCs

Table 2: A types of EDCs, their usage, target hormone and organism affected.

\begin{tabular}{|c|c|c|c|}
\hline Chemical Types & Common usage & $\begin{array}{l}\text { Target } \\
\text { hormone }\end{array}$ & Type of organism impacted \\
\hline $\begin{array}{l}\text { Polybrominated diphenyl ethers } \\
\text { (PBDEs) }\end{array}$ & Flame retardants & Thyroid & Mammals, birds, reptiles and fish \\
\hline $\begin{array}{l}\text { Dichlorodiphenyltrichloroethane } \\
\text { (DDT) }\end{array}$ & Insecticide & Estrogen & $\begin{array}{l}\text { Mammals, birds, reptiles invertebrates, } \\
\text { amphibians and fish }\end{array}$ \\
\hline Polychlorinated biphenyls (PCBs) & Industrial use & Cortisol & $\begin{array}{l}\text { Mammals, birds, reptiles, fish, } \\
\text { invertebrates and amphibians }\end{array}$ \\
\hline Cadmium & Batteries & Adrenaline & Mammals, birds and fish \\
\hline Fenoxycarb & Insecticide & Juvenile & Invertebrates \\
\hline Bisphenol A & Plasticizer & Estrogen & $\begin{array}{l}\text { Mammals, birds and fish, invertebrates, } \\
\text { amphibians }\end{array}$ \\
\hline Nonylphenol & Plasticizer & Estrogen & $\begin{array}{l}\text { Mammals, birds, fish, invertebrates, } \\
\text { amphibians }\end{array}$ \\
\hline
\end{tabular}




\section{Health Hazard and Toxicity in Humans and Laboratory Animals}

The major concern about health effects from exposure to BPA relates to its estrogen-like activity. Estrogens are a group of steroid compounds which function as the primary female sex hormone. Sex hormones influence sexual differentiation and altered levels of the hormones can have serious effects. Studies in laboratory animals exposed during development (i.e., in utero or as immature animals) provide evidence of BPA's effects on the reproductive system, including: Altered mating behavior, maternal behavior and sex-differentiated emotional and cognitive behavior. Enhancement or stimulation of breast growth in female animals. Stimulation of prostate growth in male animals.

There is some evidence that BPA has effects on the reproductive ability of adult laboratory animals. Effects on the reproductive system have been observed in adult female and male rodents.

Cancer. No information that BPA causes cancer in humans was found, and there is limited information on its potential to cause cancer in animals. The one long-term animal study reported did not find convincing evidence that BPA caused cancer in rats or mice. However, there are some animal studies to suggest further research is needed.

Obesity. Information of BPA's influence on human obesity is sparse. In animal and cell studies, BPA was found to influence multiple processes related to obesity.

Effects on the thyroid. While evidence from animal and cell studies indicates that BPA can affect the thyroid, conflicting findings have been reported. No information was found for any effects of BPA on the human thyroid.

Immune system effects. BPA has also been shown to affect the immune system of experimental animals, diminishing its ability to mount a protective response against infections.

Nervous system effects. Animal and cell studies show that BPA can affect brain development in areas linked with learning, memory and a variety of behavioral traits. There is concern that BPA might be a factor in the development of human neurological disorders such as attentiondeficit/hyperactivity disorder (ADHD) and memory loss, but there is no information on these effects in humans.

\section{Reproductive and Endocrine Toxicity}

There is sufficient qualitative information on reproductive and developmental toxicity of BPA to aquatic organisms. Crain et al. (1998) reviewed the environmental toxicology of Bisphenol A (BPA), concluding that BPA can disrupt the endocrine system of a variety of species at environmentally relevant concentrations of $21 \mu \mathrm{g} / \mathrm{L}$ or less. Reported male reproductive effects include: apotosis of testicular cells in swordtail freshwater fish (Kwak et al., 2001), inhibition of gonadal growth and spermatogenesis in fathead minnows, decreased sperm density \& motility in brown trout, reduction of testosterone and 11-ketotestosterone in turbot and induction of an intersex condition known as testis-oval| in medaka. Reported female reproductive effects include: inhibition of gonadal growth and egg production in fathead minnows, decreased hatchability of in flathead minnow larvae, delay in, or complete cessation of ovulation in brown trout, reduced number of eggs and hatchlings in medaka, induction of Atlantic salmon eggshell zona radiata protein, and increased choriogenin mRNA expression in medaka (Arukwe et al., 2000).

In Male freshwater snails (Marisa cornuarietis) and in marine dogwhelks (Nucella lapillus), BPA at concentrations ranging from 1 to $100 \mu \mathrm{g} / \mathrm{L}$ for 5 months has caused reductions in the size of the penis and prostate and decreased mature sperm in the vesicula seminalis. In female Marisa snails, enlarged accessory pallial sex glands, increased oocyte production, superfemales and oviduct malformations have been reported at concentrations as low as $1 \mu \mathrm{g}$ BPA/L (Oehlmann et al., 2006). Superfemales are characterized by the formation of additional female organs, enlarged accessory sex glands, gross malformations of the pallial oviduct and a stimulation of egg and clutch production, resulting in increased female mortality.

BPA concentrations of $20 \mu \mathrm{g} / \mathrm{L}$ for 10 days induced maturation of reproductive organs and egg production in female copepods, small crustaceans found in marine and freshwater habitats. Similar effects were seen at concentrations of 2 and $0.2 \mu \mathrm{g} / \mathrm{L}$, but they were not statistically significant at these levels (Andersen et al., 1999). Long-term exposure of the copepod Tigriopus japonicus to $0.1,1.0$ and $10 \mu \mathrm{g} / \mathrm{L}$ BPA caused a significant delay in completion of the naupliar stages compared to the controls in the parental generation, and at $0.01 \mu \mathrm{g} / \mathrm{L}$ and above in the F1 generation (Crain et al., 2008)). BPA concentrations as low as $0.08 \mu \mathrm{g} / \mathrm{L}$ delayed emergence of F2 male and female midges Chironomus riparius. At $10,400 \mu \mathrm{g} / \mathrm{L} \mathrm{BPA}$, it completely inhibited egg hatching and emergence of the F2 generation.

\section{Reproductive and Developmental Effects}

BPA is among the chemicals identified as a potential endocrine disruptor based on its estrogenic properties. Studies in laboratory animals have focused on understanding the consequences of BPA for estrogenic activity, taking into account the variety of estrogen receptors (ER) and estrogen binding molecules and their functions in different reproductive processes and different stages of the life cycle. Estrogen has a pervasive effect on body function in both males and females through a variety of mechanisms. The action of BPA at ER $\alpha, E R \beta$, estrogen related receptor (ERR) and the estrogen membrane receptor (mER) has been documented (Wetherill et al., 2007). Epigenetic effects of BPA have also been demonstrated. Further, the estrogen receptor belongs to a large family of gene products, the nuclear steroid hormone receptor superfamily, which have some ligand cross reactivity. This family of nuclear receptors is present in all known vertebrates. For example, both estrogen and BPA bind to the thyroid receptor and antagonize the androgen receptor (Wetherill et al., 2007).

The mammalian endocrine system is very active and undergoes frequent physiological changes due to cyclic hormonal feedback systems and diurnal variations. Typically, the endocrine system comprises of several brain regions (such as the hypothalamus and pineal) and glands (pituitary, thyroid, pancreas, adrenal, ovary, testis and placenta) (Figure 6). 


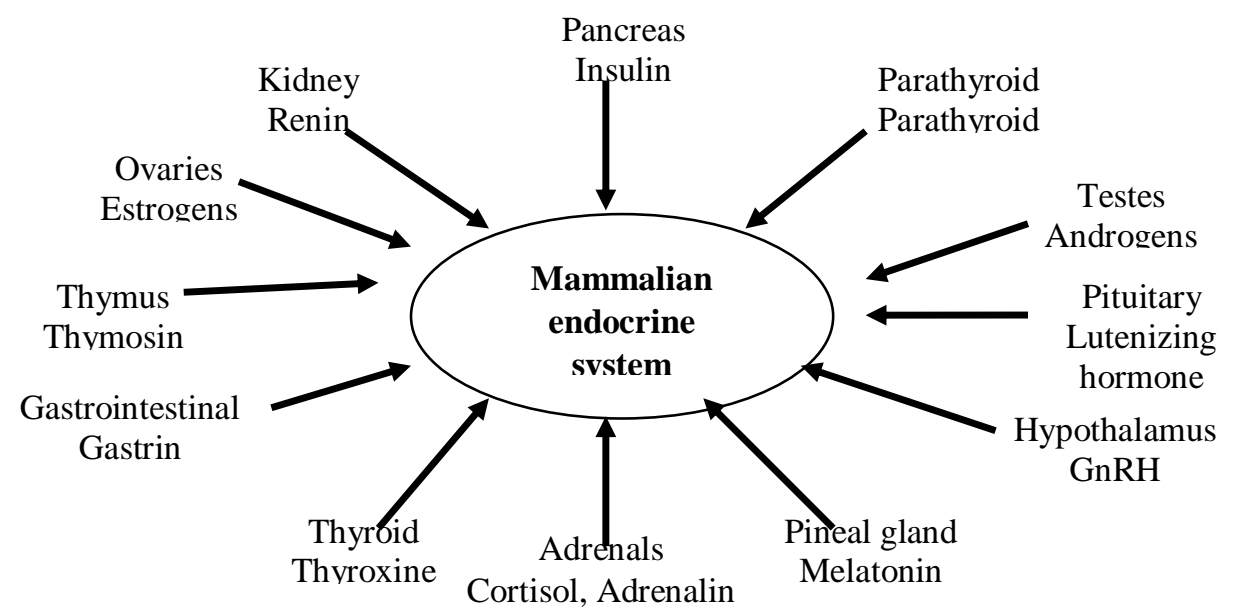

Figure 6: Glands and tissues of the endocrine system and hormones produced by them.

\section{EXPERIMENTAL PART}

\section{Animals}

The study was conducted in Wistar rats. The animals were maintained under the standard laboratory conditions (temperature $25 \pm 2{ }^{\circ} \mathrm{C}$; photoperiod of $12 \mathrm{~h}$ ). Commercial pellet diet and water were given ad libitum.

\section{Isolation of Mitochondria}

Mitochondria were isolated according to the method of Sayeed et al. (2006). All procedures were carried out on ice or at $4 \stackrel{\circ}{\circ}$. Testes were minced in fresh isolation medium and gently homogenized manually $(10 \% \mathrm{w} / \mathrm{v}$ in isolation medium) using a homogenizer with a loose fitting pestle. The homogenate was centrifuged at $500 \mathrm{xg}$ for $10 \mathrm{~min}$. The supernatant fraction was retained and the pellet was washed with fresh isolation medium and recovered by the initial supernatant fraction. The pooled fractions were centrifuged at $500 \mathrm{x}$ g for $10 \mathrm{~min}$. The supernatant thus obtained was centrifuged at $5000 \mathrm{x}$ g for $15 \mathrm{~min}$ to obtain the mitochondrial pellet. The pellet was washed first with isolation medium and then with respiration reaction buffer (70 mM sucrose, $220 \mathrm{mM}$ mannitol, $2 \mathrm{mM}$ HEPES, $0.5 \mathrm{mM}$ EDTA, $2.5 \mathrm{mM} \mathrm{MgCl} 2,0.5 \mathrm{mM} \mathrm{KH}_{2} \mathrm{PO}_{4}, 2 \mathrm{mM} \mathrm{K}_{2} \mathrm{HPO}_{4}$, (pH 7.4). The purifed mitochondria were obtained by centrifugation at $12,000 \mathrm{x} \mathrm{g}$ for $10 \mathrm{~min}$. The final mitochondrial pellet was re-suspended in respiration reaction buffer ( $1 \mathrm{ml} / \mathrm{g}$ tissue) to produce a suspension containing 25-40 mg of mitochondrial pellet $/ \mathrm{ml}$.

\section{Necropsy}

After termination of treatment animals were sacrificed under mild anesthesia and their testes were taken out and washed with ice cold saline $(0.9 \% \mathrm{NaCl})$. After washing in ice cold isolation medium $(0.25 \mathrm{M}$ sucrose $)$ and $1 \mathrm{mM}$ EDTA $(\mathrm{pH}$ 7.4) testes were gently blotted between the folds of filter paper and weighed.

Table 3: Bispinol A and other control group.

\begin{tabular}{ll} 
Number of Group & Dose and Control \\
\hline Group I & Corn Oil (Control) \\
Group II & BPA (5 mg/kg body weight) \\
Group III & BPA (10 mg/kg body weight) \\
Group IV & BPA (100 mg/kg body weight) \\
\hline
\end{tabular}

Animals were divided into four groups of three animals each. Group I was administered orally with corn oil $(0.2 \mathrm{ml})$ only which served as control. Group II was administered BPA suspended in corn oil at $5 \mathrm{mg} / \mathrm{kg}$ body weight per day. Group III received $10 \mathrm{mg} / \mathrm{kg}$ body weight BPA orally. Group IV received $B P A 100 \mathrm{mg} / \mathrm{kg}$ orally. For light microscopy two studies were performed one in which the dosing was carried out for duration of 7 days and other for 14 days orally. For transmission electron microscopy dosing was done for the duration of 14 days orally. Doses of BPA based on studies published by (Tachibana et al., 2007). Animals were sacrificed by cervical dislocation under mild anesthesia and their testes were removed and used for histopathological study.

\section{Toxicological Study}

The result establishes oxidative stress inducing effects of BPA in testicular mitochondria of Wistar Rat as well as BPA induced alterations in mitochondrial marker enzymes and hence caused mitochondrial dysfunction. Estrogenic compounds (Xenoestrogensx) may cause deformity of reproductive organs and impaired sexual behavior (Berg et al., 1999). Reports suggest that the human semen quality has declined during the last 60 years and the incidence of male genital tract abnormalities and infertility has also increased (Maffini et al., 2006). About $10-15 \%$ of human populations suffer from health problems related to infertility, and half of those are male (Seshagiri, 2001). As living standards of human beings have improved, particular attention has been paid to the connection between male reproductive health and the environment (Knez, 2013). Animal studies suggest that xenoestrogens alter the development, functions, and cause cancer of the male reproductive system (Fusani et al., 2007). The detection of EDCs in the environment, biota and humans is of concern due to their potential to interfere with the physiology of living organisms (Oehlmann et al., 2009). Humans take up these environmental toxicants by ingestion of contaminated food and water, usage of consumer products 
(e.g. plasticware and cosmetics) and inhalation of polluted air (Aitken et al., 2004).

The toxicity caused by BPA exposure in testicular tissue of Wistar Rat. Light microscopic examination of samples was done to evaluate the possible changes caused by treatment of three different doses of BPA. After getting the results in light microscopy we decided to observe the changes and damage caused by BPA ultrastructural. We critically analyzed the samples by use of transmission electron microscope to find the changes in testis on exposure to BPA. The aim was to find out whether BPA is capable of causing ultrastructure changes and toxicity in testicular mitochondria. Not much is known about the effects of BPA on cell in general and organelle like mitochondria in particular. So in this study we have focused on that aspect.

\section{RESULTS AND DISCUSSION}

\section{Light microscopic changes}

In case of control testis samples uniform arrangement of layers in the seminiferous tubules was identified (Figure 7A, 7B). At the lower ( $5 \mathrm{mg} / \mathrm{kg}$ ) dose of BPA for 7 days there was no histological changes observed in the tissues of testis (Figure 7C, 7D) of Rat. Histological examination of these sections of testis showed seminiferous tubules of normal shape and size. In the sections of testis samples treated with $10 \mathrm{mg} / \mathrm{kg}$ dose of BPA for 7 days histological examination showed seminiferous tubules of normal shape and size (Figure 7E, 7F). At the higher dose of BPA (100 mg/kg) for 7 days there was no histological change observed in the section of testis and there was uniform arrangement of cell layers in the seminiferous tubule (Figure 7G, 7H).

In case of control testis samples uniform arrangement of layers in the seminiferous tubules was identified showing normal shape and size (Figure 8A, 8B). High power photomicrograph of mouse treated with BPA $5 \mathrm{mg} / \mathrm{kg}$ (Figure 8D) for 14 days showed mild reduction in cell numbers in the layers of the seminiferous tubule. On high power examination of testis of mouse treated with BPA 10 $\mathrm{mg} / \mathrm{kg}$ (Figure $8 \mathrm{~F}$ ) for 14 days also reveal reduction of cells in the layers of seminiferous tubule. In case of higher dose group BPA $100 \mathrm{mg} / \mathrm{kg}$ (Figure $8 \mathrm{H}$ ) for 14 days histological changes were observed. This section of the testis shows disruption of the normal arrangement of cells in the seminiferous tubule. This tubule is in Stage 2 of the spermatogenetic cycle. Portions of the tubule (arrow) (Figure $8 \mathrm{H}$ ) show disappearance of cells and prominent vacuolar change.

Figure 7. Histopathological changes in testicular tissue of Rat exposed to bisphenol A for 7 days.
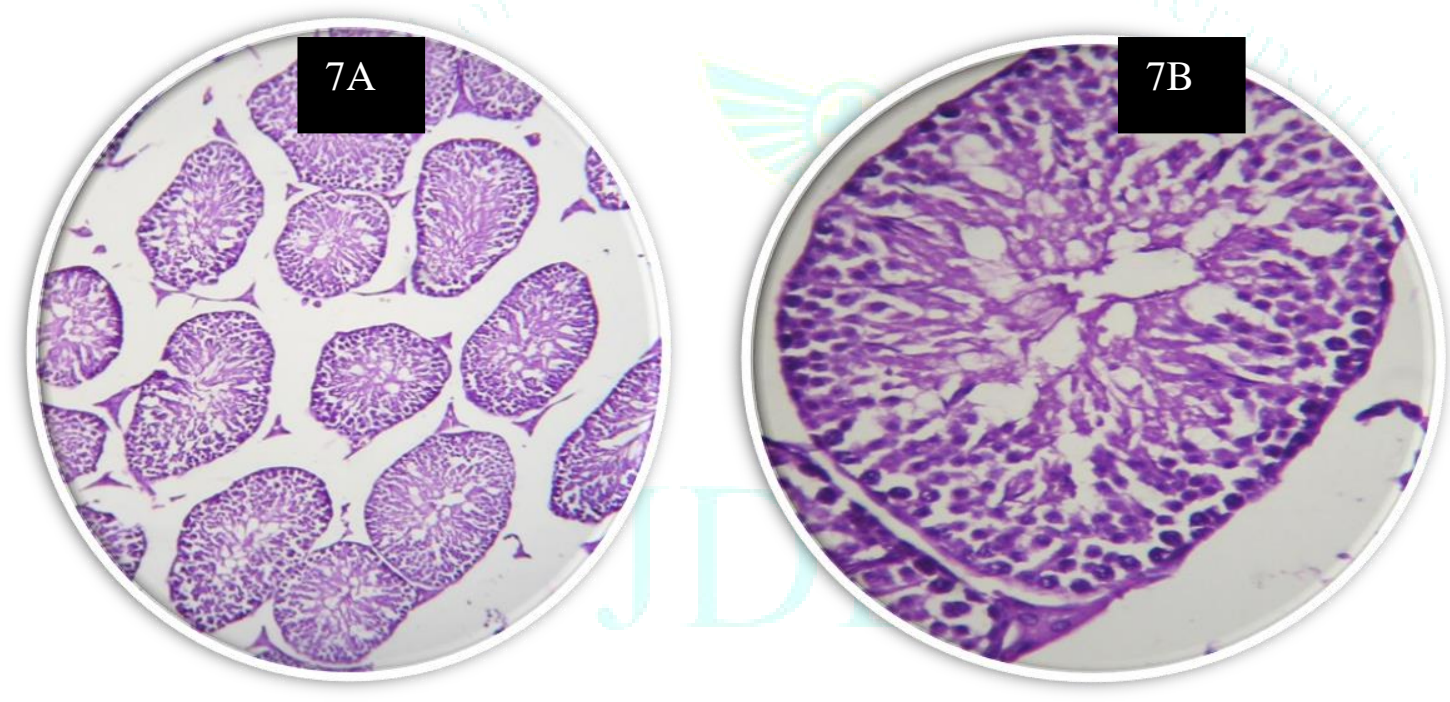

Figure 7A. Grp 1 100x. Photomicrograph of testis from control group animal showing seminiferous tubules of normal shape and size.

Figure 7B. Grp 1. 400x. Photomicrograph of same section showing uniform arrangement of layers in the seminiferous tubule. This tubule is in Stage 3 of the spermatogenetic cycle. 

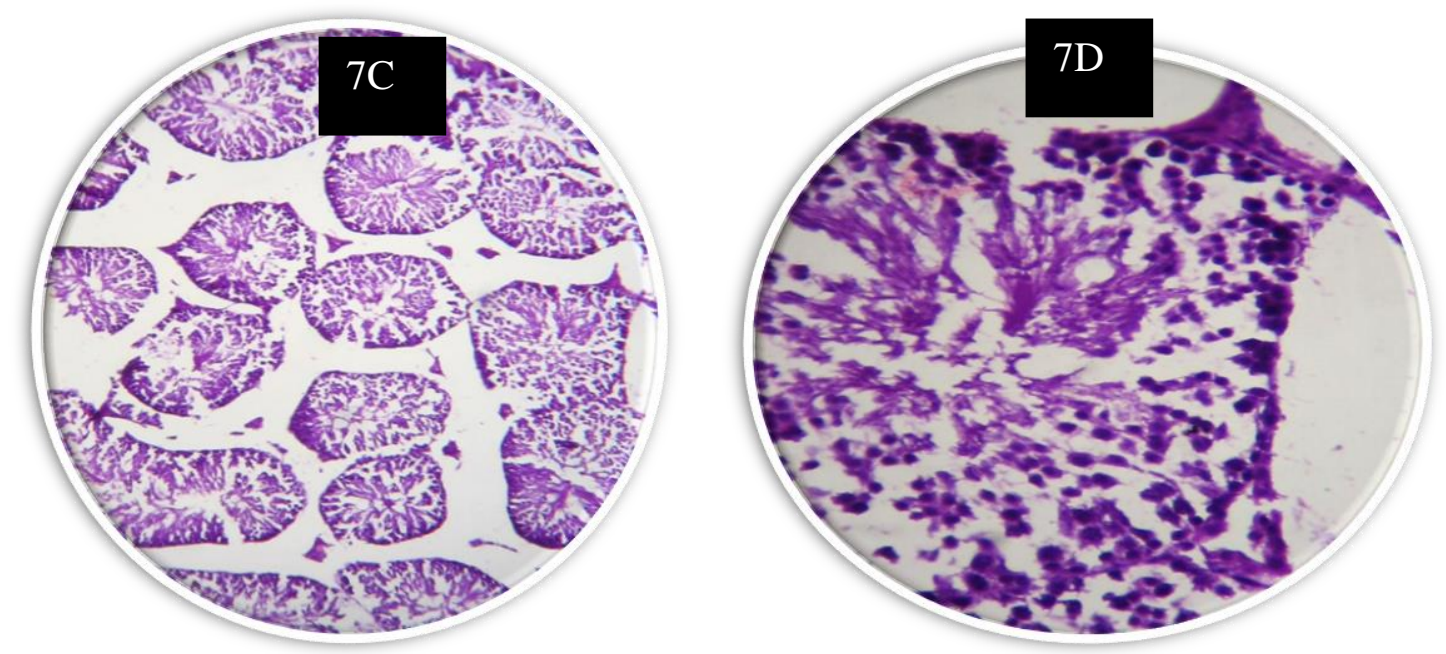

Figure 7C. Grp II 100x. Photomicrograph of testis from animal that received $5 \mathrm{mg} / \mathrm{kg}$ body wt of BPA showing seminiferous tubules of normal shape and size.

Figure 7D. Grp II 400x. Photomicrograph of same section showing uniform arrangement of layers in the seminiferous tubule. This tubule is also in Stage 3 of the spermatogenetic cycle.
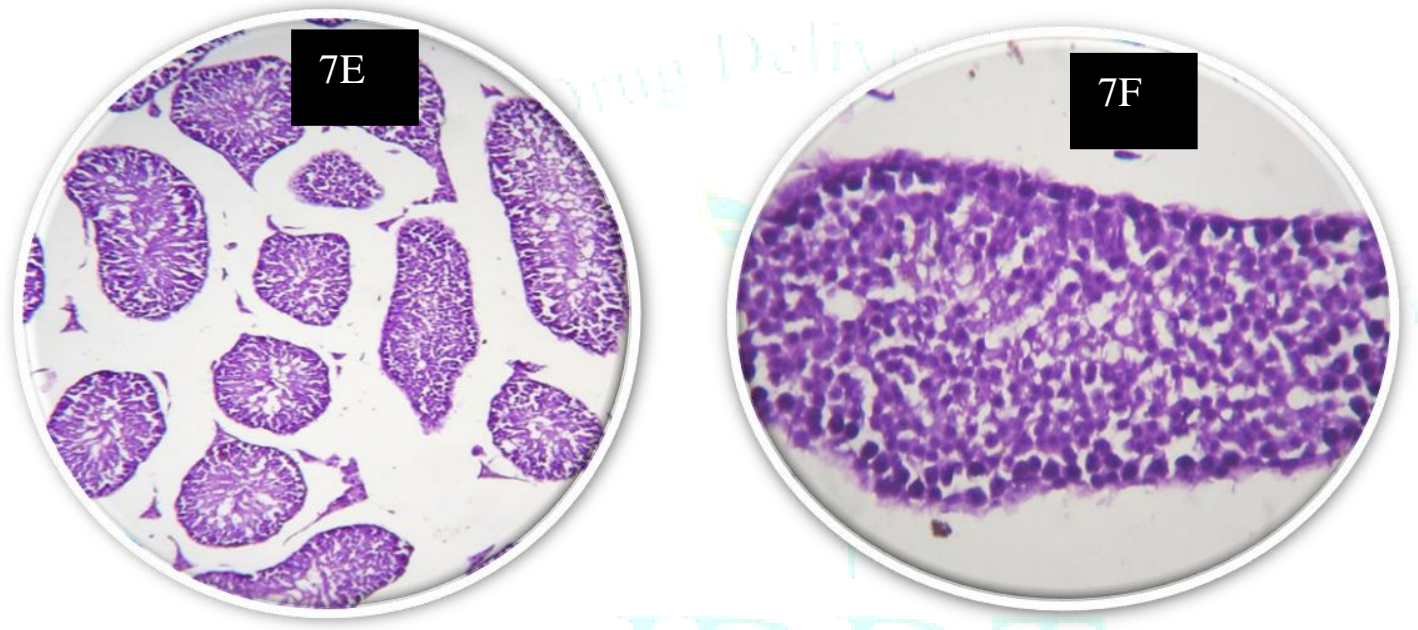

Figure 7E. Grp III 100x. Photomicrograph of testis from animal that received $10 \mathrm{mg} / \mathrm{kg}$ body wt of BPA showing seminiferous tubules of normal shape and size.

Figure 7F. Grp III 400x. Photomicrograph of same section showing uniform arrangement of layers in the seminiferous tubule. This tubule is in Stage 5 of the spermatogenetic cycle.
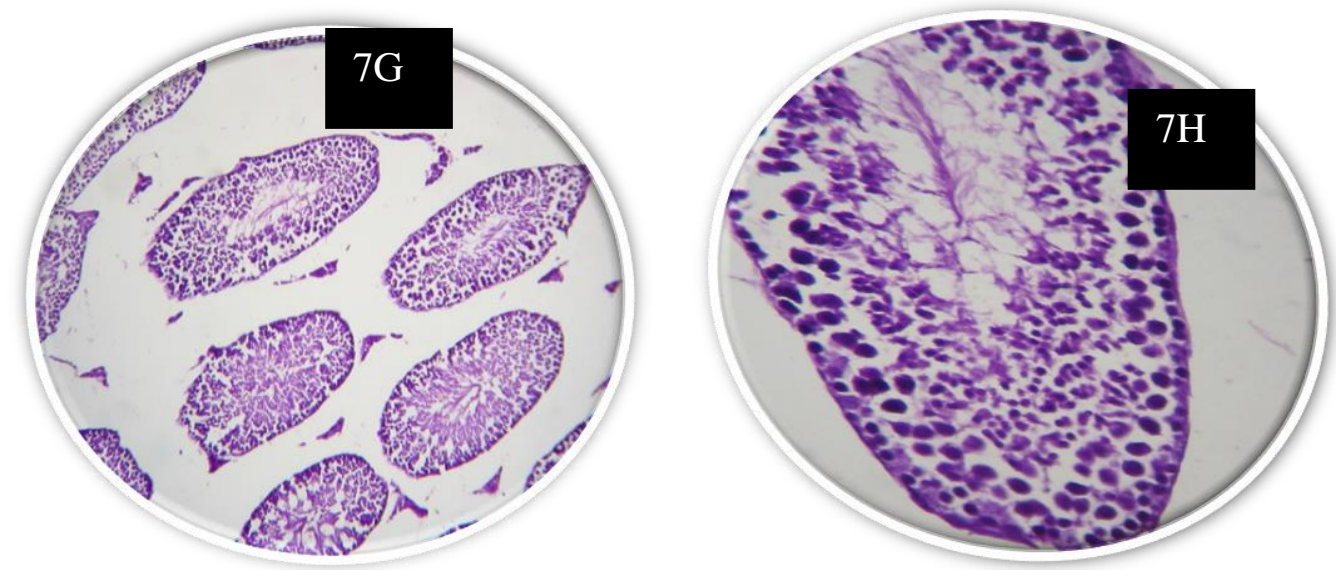

Figure 7G. Grp IV 100x. Photomicrograph of testis from animal that received $100 \mathrm{mg} / \mathrm{kg}$ body wt of BPA showing obliquely cut seminiferous tubules of normal shape and size.

Figure 7H. Grp IV 400x. Photomicrograph of same section showing uniform arrangement of layers in the seminiferous tubule. This tubule is in Stage 2 of the spermatogenetic cycle. 
Figure 8. Histopathological changes in testicular tissue of Rat exposed to BPA for 14 days
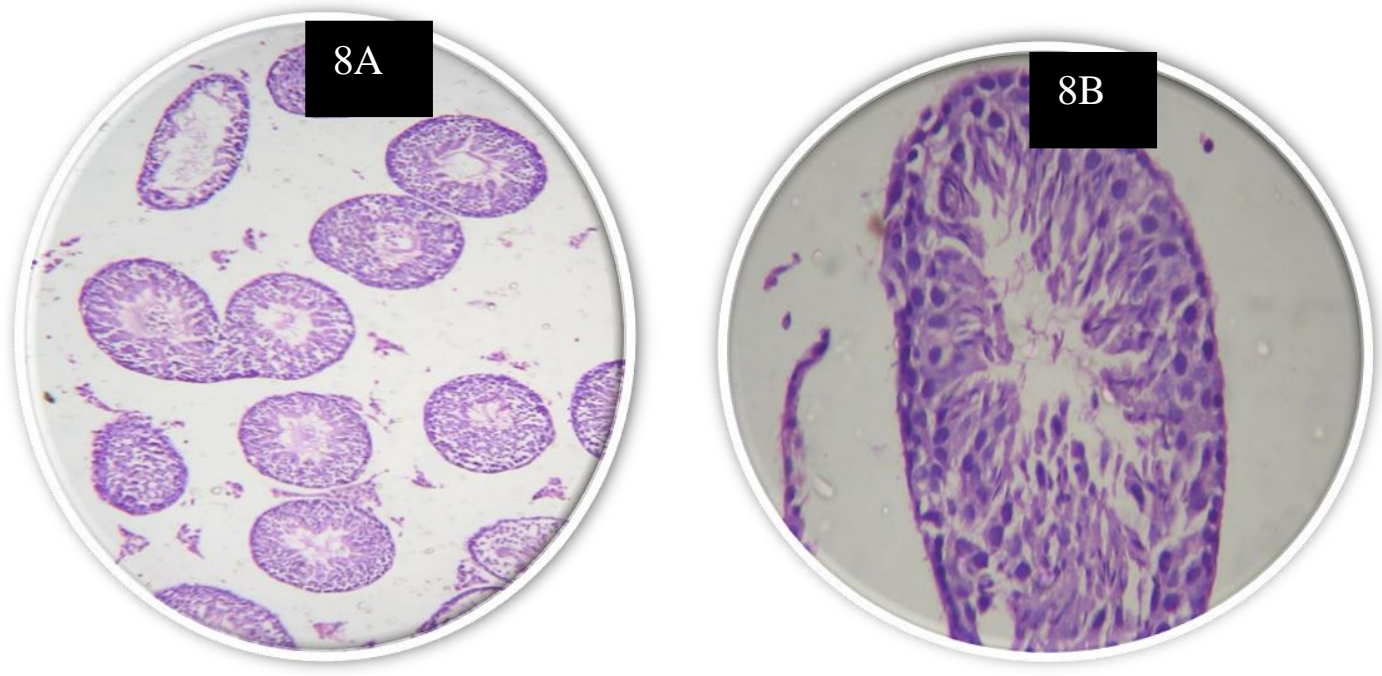

Figure 8A. Grp 1 100x. Photomicrograph of testis from control group animal showing seminiferous tubules of normal shape and size.

Figure 8B. Grp 1 400x. Photomicrograph of same section showing uniform arrangement of layers in the seminiferous tubule. This tubule is in Stage 6 of the spermatogenetic cycle.
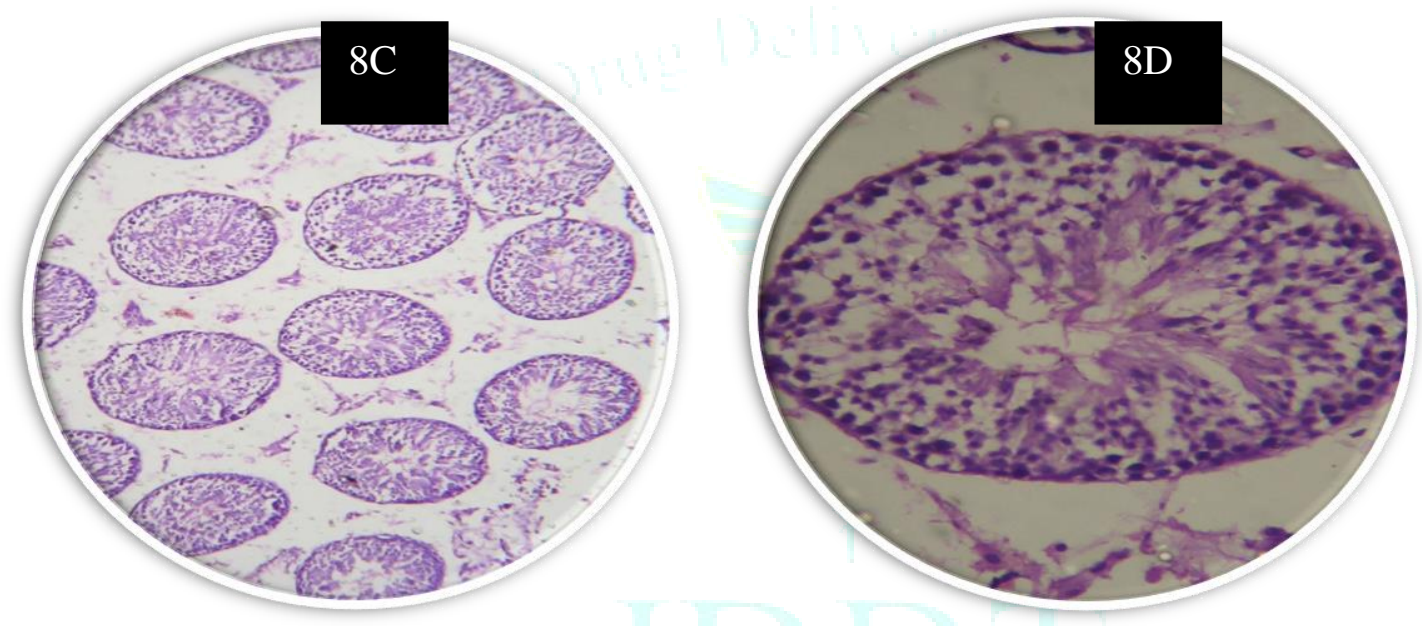

Figure 8C. Grp II 100x. Photomicrograph of testis from animal that received $5 \mathrm{mg} / \mathrm{kg}$ body wt of BPA showing seminiferous tubules of normal shape and size.

Figure 8D. Grp II 400x. Photomicrograph of same section showing a tubule in Stage 6 of the spermatogenetic cycle. There is a mild reduction in cell numbers in the layers of the seminiferous tubule.
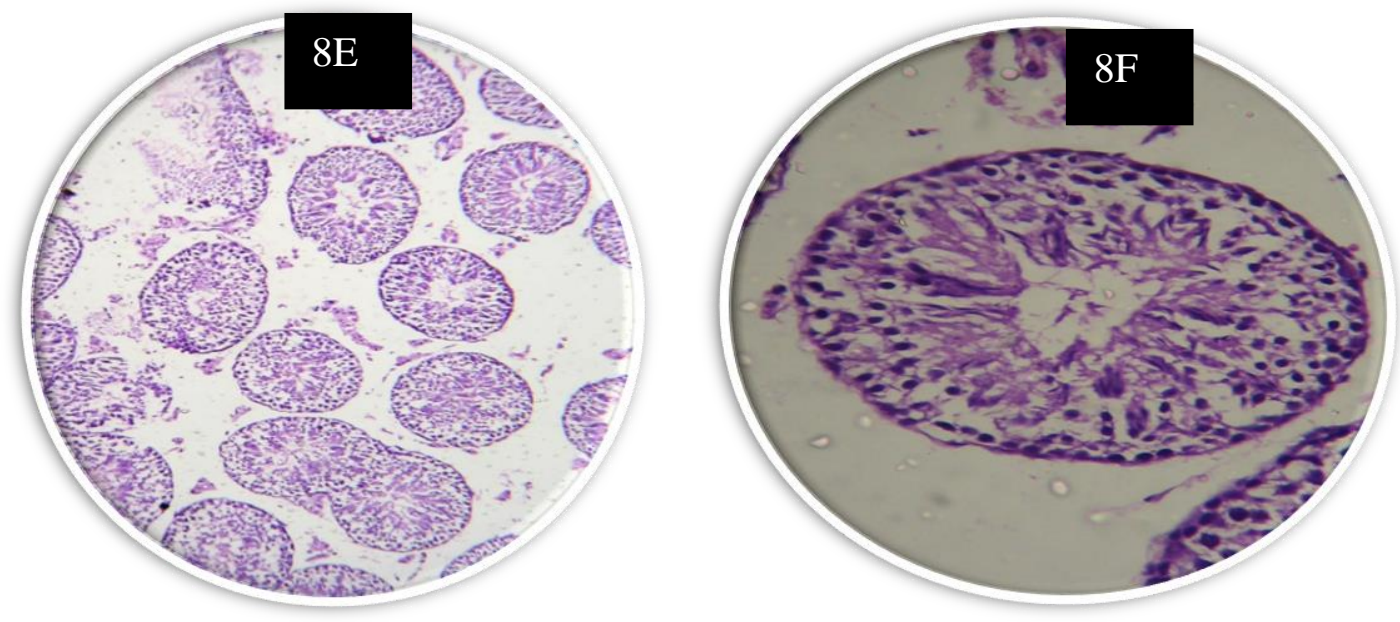

Figure 8E. Grp III 100x. Photomicrograph of testis from animal that received $10 \mathrm{mg} / \mathrm{kg}$ body wt of BPA showing seminiferous tubules of normal shape and size.

Figure 8F. Grp III 400x. Photomicrograph of same section showing a tubule in Stage 6 of the spermatogenetic cycle. Only a mild reduction of cells in the layers of the seminiferous tubule is seen. 

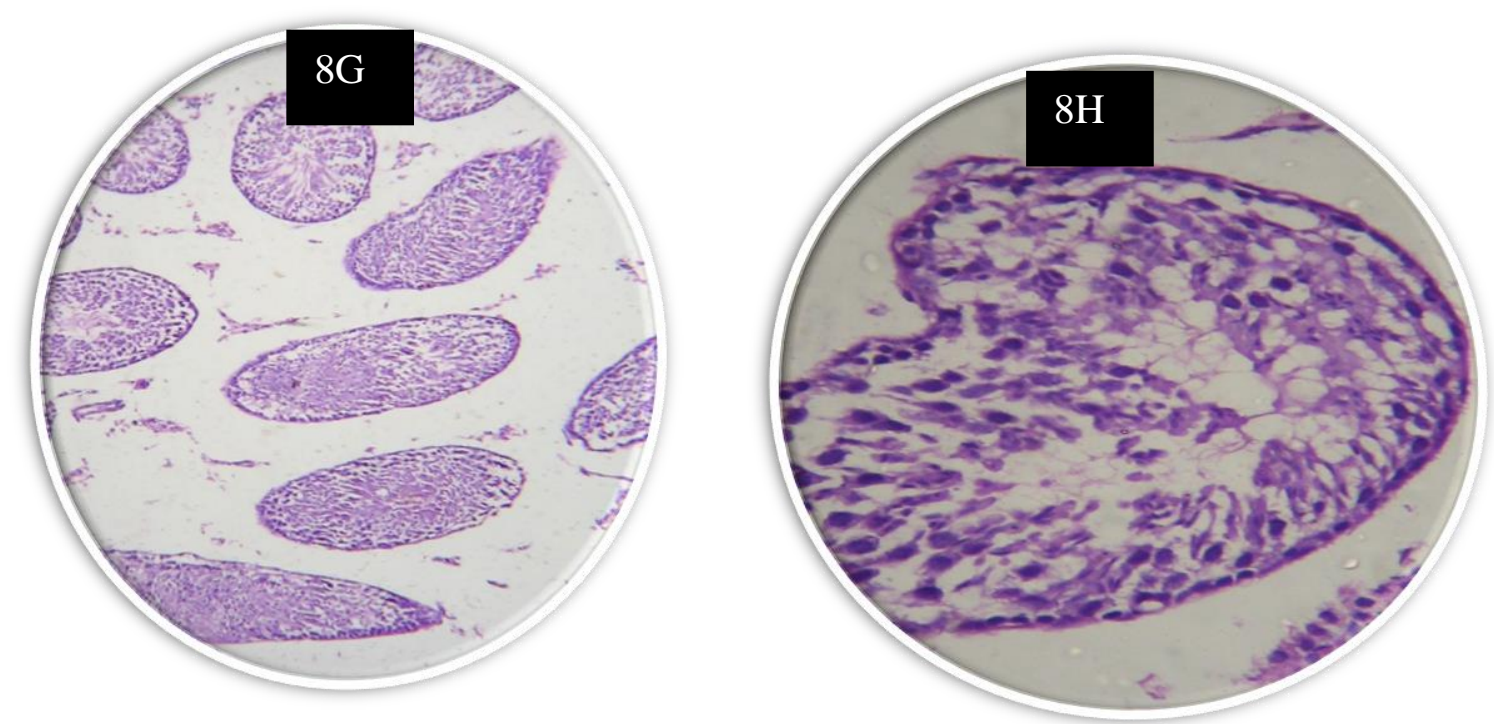

Figure 8G. Grp IV 100x. Photomicrograph of testis from animal that received $100 \mathrm{mg} / \mathrm{kg}$ body wt of BPA showing obliquely cut seminiferous tubules of normal shape and size.

Figure 8H. Grp IV 400x. Photomicrograph of same section showing disruption of the normal arrangement of cells in the seminiferous tubule. This tubule is in Stage 2 of the spermatogenetic cycle. Portions of the tubule show disappearance of cells and prominent vacuolar change.

There were many ultra-structural changes found in the treated groups as compared to the control group. Studies suggest that BPA exposure causes ultra-structural changes in testis of rodents (Toyama and Yuasa, 2004). The basement membrane of seminiferous tubules showed abnormality. It became wavy, thick and distorted. Basement membrane is the membrane covering the seminiferous tubules of the testes. BPA treatment caused membrane damage of the seminiferous tubules. Membranes are made up of lipids and BPA causes LPO in the membranes. The damage increased as the dose of BPA increased.

BPA negatively affected male germ cell number and hence may affect fertility. BPA causes release of ROS and oxidative stress in mitochondria of testes. These free radicals generated are having the potential to adversely affect the germ cell and is components. There are evidences that ROS can induce apoptosis via several mechanisms, including mitochondria-dependent or independent pathway in various cell lines and tissues (Zhang et al., 2011). Mitochondria provide the gateway through which apoptosis can be executed in a rapid and robust manner (Dan et al., 2005). BPA affected activities of vital enzymes of mitochondria which are part of mitochondrial bioenergetics as well as reduced glutathione levels. Ultra structurally BPA causes apoptosis of spermatogenic cells in the testes.

There were many ultra-structural changes found in the treated groups as compared to the control group. Studies suggest that BPA exposure causes ultrastructural changes in testis of rodents (Toyama and Yuasa, 2004). The basement membrane of seminiferous tubules showed abnormality. It became wavy, thick and distorted. Basement membrane is the membrane covering the seminiferous tubules of the testes. BPA treatment caused membrane damage of the seminiferous tubules. Membranes are made up of lipids and BPA causes LPO in the membranes. The damage increased as the dose of BPA increased.

Another significant change which was observed was the detachment of the basal cells. The spermatogenic cells attached to the basal membrane showed detachment and also decreased in number as compared to control group. The decrease in number of spermatogenic cells shows that apoptosis may have occurred and cells might have died. Destruction of the spermatogonial complement of the testis results in sterility. Also vacuolization was observed in these cells. Study has also confirmed that BPA caused apoptosis in testicular cells. Spermatocyte and spermatogonia were affected by BPA treatment in our study. A study showed that low concentration of BPA caused spermatogenic and Sertoli cells to apoptosis, whereas a higher concentration tend to lead spermatogenic and Sertoli cells to necrosis in goat (Andriana et al, 2004). Transmission electron microscopy observation shows that BPA treatment caused apoptosis in sertoli cells as well as spermatogonia. The nucleus of spermatocyte and spermatogonia showed chromatin clumping and marginization. The nuclear membrane showed convolutions and shape of nucleus highly distorted. Apoptotic spermatogonia were characterized by a ruptured nucleus, shrinkage of the cytoplasm and nucleus, and still functioning cell organelles (Andriana et al., 2004).

Mitochondria are target of BPA and it causes mitochondrial membrane permeability transition has been shown by Kashiwagi et al., (2008). The mitochondria present in the spermatogonia and sertoli cells showed swelling. It could be early signs of apoptosis. These ROS could also cause apoptosis of the Sertoli and spermatogenic cells in the seminiferous tubules of the testicular tissue. A study has shown that BPA and some related phenols are cytotoxic, most likely through the impairment of mitochondrial function and consequent decrease in the cellular level of ATP (Nakagawa and Tayama, 2000). Also compound bisphenol A diglycidyl ether-induced apoptosis involves Bax/Bid dependent mitochondrial release of apoptosis-inducing factor (AIF), cytochrome c and Smac/DIABLO. Cristae of mitochondria were absent in many mitochondria of Sertoli cell in animals treated with BPA. This may be due to oxidative stress, $\mathrm{Ca} 2+$ overload, and ATP loss perhaps due to Bax-mediated effects and this shows mitochondria mediated apoptosis (Perkins et al., 2012).

There were structural changes in spermatids of treated group as compared to control ones. Chromatin clumping 
was also seen in the nucleus of spermatids. The normal shape and structure of spermatid was altered. There was abnormality in the head region of spermatid as compared to control group. The spermatids showed deformation of the nucleus and abnormal shape of the acrosomal cap. The acrosome of a developing spermatid was abnormally protruded and it took the shape of hammer. Ectoplasmic specialization between Sertoli cell and developing spermatids were severely affected. Adjacent to the cell membrane of spermatids, the Sertoli cell demonstrate parallel cisternae of endoplasmic reticulum, which delineate a narrow band of cytoplasm containing bundles of fibrils which is known as ectoplasmic specialization. The ectoplasmic specialization contains layer of actin filaments. Incomplete ectoplasmic specialization was observed between sertoli cell and adjoining developing spermatids of treated group as compared to control group.

BPA affected activities of vital enzymes of mitochondria which are part of mitochondrial bioenergetics as well as reduced glutathione levels. Ultra structurally BPA causes apoptosis of spermatogenic cells in the testes. Apoptosis caused by BPA may be manifested as a result of release of ROS in the testicular tissue, which is also inferred by the reduced levels of GSH and decrease of mitochondrial marker enzymes. At molecular level BPA interferes with the development process of sperm by interacting with the estrogen receptors. BPA affected different type of cells in various stages of sperm development in the seminiferous tubules. It affected spermatogonia, spermatocyte, sertoli cell and developing spermatids. Infertility is a major problem now a days and by the results received by us we can infer that environmental endocrine chemical BPA is a potent endocrine disruptor and has potential to cause testicular toxicity. These findings suggest that BPA may cause testicular toxicity by impacting various testicular cell types and by activating the mitochondrial apoptotic pathway. However, given that human exposure to low level of BPA is continuous and BPA can bio accumulate in some conditions, there is concern about human reproductive health especially for occupational workers exposed to higher levels of BPA.

\section{CONCLUSION}

The present study establishes BPA induced alterations in mitochondrial marker enzymes and hence cause mitochondrial dysfunction. Studies were performed to evaluate the histopathological changes in testes tissue on exposure to different doses of BPA for different time periods. Light microscopic examination of samples was done to evaluate the possible changes caused by treatment of different doses of BPA. After getting the results in light microscopy the changes and damage caused by BPA ultrastructurally were observed.

Light microscopic study showed that BPA exposure for short duration of 7 days did not resulted in significant change in testicular histology of Rat of treated animals. In case of control testis samples uniform arrangement of layers in the seminiferous tubules was identified. Light microscopic observations showed that low doses of BPA ( 5 and $10 \mathrm{mg} / \mathrm{kg}$ body weight) exposure for 14 days caused reduction in the number of cells in the layers of seminiferous tubules. Highest dose of BPA treatment for 14 days caused much damage to the seminiferous tubules and the tubule is in stage 2 of the spermatogenetic cycle. There were many ultra-structural changes found in the treated groups as compared to the control group.

\section{REFERENCES}

1. Sajiki J, Yonekubo J. 2004. Leaching of Bisphenol A (BPA) from Polycarbonate Plastic to WaterContaining Amino Acids and Its Degradation by Radical Oxygen Species. Chemosphere 55: 861-867.

2. Miao S, Kou Z, Gao Z. 2009. Effect of bisphenol A on the structure of organs and the expression of some cytokines in rats. Journal of hygeine research. 38:11-4.

3. Dobrzynska MM, Radzikowska J. 2010. Frequency of micronuclei in reticulocytes of male mice exposed to bisphenol A and to a combination of x-rays and bisphenol A. Rocz. Panstw. Zakl. Hig. 61:129-133.

4. Schecter A, Malik N, Haffner D, Smith S, Harris TR, Paepke O, Birnbaum L. 2010. Bisphenol A (BPA) in U.S. Food. Environ. Sci. Technol. 44:9425-9430.

5. Liao C, Kannan K. 2011. Occurrence of Bisphenol A in Paper and Paper Products: Implications for Human Exposure. Environ. Sci. Technol. 45: 9372-9379.

6. Morrissey RE, George JD, Price CJ, Tyl RW, Marr MC, Kimmel CA. 1987. The developmental toxicity of Bisphenol A in rats and mice. Fundam. Appl. Toxicol. 8:571-582.

7. Krishnan AV, Stathis P, Permuth SF, Tokes L, Feldman D. 1993. Bisphenol-A: an estrogenic substance is released from polycarbonate flasks during autoclaving. Endocrinology 132:2279-2286.

8. Chun TY, Gorski J. 2000. High concentrations of bisphenol A induce cell growth and prolactin secretion in an estrogenresponsive pituitary tumor cell line. Toxicol. Appl. Pharmacol. 162: 161-165.

9. Brotons JA, Olea-Serrano MF, Villalobos M, Pedraza V, Olea N. 1995. Xenoestrogens released from lacquer coatings in food cans. Environ. Health Perspect. 103:753-758.

10. Yoo SD, Shin BS, Kwack SJ, Lee BM 2000: Pharmacocinetic disposition and tissue distribution of bisphenol $\mathrm{A}$ in rats after intravenous administration. J Toxicol. Environ. Health A 61:131-139.

11. Wetherill Y B, Akingbemi B, Kanno J, McLachlan J A, Nadal A, Sonnenschein C, Watson J A,

12. Nakagawa Y, Tayama S. 2000. Metabolism and cytotoxicity of bisphenol A and other bisphenols in isolated rat hepatocytes. Arch. Toxicol. 74:99-105.

13. Monroe RK, Halvorsen SW. 2009. Environmental toxicants inhibit neuronal Jak tyrosine kinase by mitochondrial disruption. Neurotoxicology 30:589-598.

14. IPCS. 2002. Global assessment of the state-of-the-science of endocrine disruptors. In: Damstra T, Barlow S, Bergman A, Kavlock R, Kraak Van der. (eds.), International Programme on Chemical Safety: World Health Organisation.

15. Belluzzi E, Bisaglia M, Lazzarini E, Tabares LC, Beltramini M, Bubacco L. 2012. Human SOD2 modification by dopamine quinones affects enzymatic activity by promoting its aggregation: possible implications for Parkinson's disease. PLoS One 7:e38026.

16. Kwak HI, Bae MO, Lee MH, Lee YS, Lee BJ, Kang KS, Chae CH, Sung HJ, Shin JS, Kim JH, Mar WC, Sheen YY, Cho MH. 2001. Effects of nonylphenol, bisphenol A, and their mixture on the viviparous swordtail fish (Xiphophorus helleri). Environ. Toxicol. Chem. 20:787-95.

17. Sayeed I, Parvez S, Winkler-Stuck K, Seitz G, Trieu I, Wallesch CW, Schonfeld P, Siemen D. 2006. Patch clamp reveals powerful blockade of the mitochondrial permeability transition pore by the D2-receptor agonist pramipexole. FASEB J 20:556-558.

18. Howdeshell KL, Hotchkiss AK, Thayer KA, Vandenbergh JG, Vom Saal. 1999. Environmental Toxins: Exposure to Bisphenol A Advances Puberty. Nature 401:763- 764.

19. Ceccarelli I, Della Seta D, Fiorenzani P, Farabollini F, Aloisi AM. 2007. Estrogenic chemicals at puberty change ERalpha in the hypothalamus of male and female rats. Neurotoxicol. Teratol. 29:108-15

20. Takayanagi S, Tokunaga T, Liu X, Okada H, Matsushima A, Shimohigashi Y. 2006. Endocrine disruptor bisphenol A strongly binds to human estrogen-related receptor gamma (ERRgamma) with high constitutive activity. Toxicol. Lett. 167:95-105. 
21. Bartsch H, Nair J. 2000. Ultrasensitive and specific detection methods for exocyclic DNA adducts: markers for lipid peroxidation and oxidative stress. Toxicology 153:105-114.

22. Sun Y. 1990. Free radicals, antioxidant enzymes, and carcinogenesis. Free Radical Biol. Med. 8:583-599.

23. Kayanoki Y, Fuji J, Islam KN, Kawata S, Matsuzawa Y, Taniguchi N. 1996. The protective role of glutathione peroxidase in apoptosis induced by reactive oxygen species. J Biochem. 119:817-822.

24. Tachibana T, Wakimoto $\mathrm{Y}$, Nakamuta N, Phichitraslip T, Wakitani S, Kusakabe K, Hondo E, Kiso Y. 2007. Effects of bisphenol A (BPA) on placentation and survival of the neonates in mice. J. Reprod. Dev. 53:509-514.

25. Maffini MV, Rubin BS, Sonnenschein C, Soto AM. 2006. Endocrine disruptors and reproductive health: The case of bisphenol-A. Mol. Cell. Endocrinol. 254-255:179-186.

26. Seshagiri PB. 2001. Molecular insights into the causes of male infertility. J. Biosci. 26:429-435

27. Knez J. 2013. Endocrine-disrupting chemicals and male reproductive health. Reprod. Biomed. Online. doi:pii: S14726483(13)00069-2. 10.1016/j.rbmo.2013.02.005. [Epub ahead of print].

28. Fusani L, Della Seta D, Dessì-Fulgheri F, Farabollini F. 2007. Altered reproductive success in rat pairs after environmentallike exposure to xenoestrogen. Proc. Biol. Sci. 274:1631-6.
29. Aitken RJ, Koopman P, Lewis SE 2004. Seeds of concern. Nature 432:48-52.

30. Toyama Y, Yuasa S. 2004. Effects of neonatal administration of $17 \beta$-estradiol, $\beta$-estradiol, 3-benzoate, or bisphenol A on mouse and rat spermatogenesis. Reprod. Toxicol. 19:181-188.

31. Dan Z, Popov Y, Patsenker E, Preimel D, Liu C, Wang XD, Seitz HK, Schuppan D, Stickel F. 2005. Hepatotoxicity of alcoholinduced polar retinol metabolites involves apoptosis via loss of mitochondrial membrane potential. FASEB J. 19:845-7.

32. Andriana BB, Tay TW, Hiramatsu R, Awal MA, Kanai Y, Kurohmaru M, Hayashi Y. 2004. Bisphenol A-induced morphological alterations in Sertoli and spermatogenic cells of immature Shiba goats in vitro: An ultrastructural study. Reproductive Medicine and Biology 3:205-210.

33. Kashiwagi A, Utsumi K, Kashiwagi K, Ohta S, Sugihara K, Hanada H, Kitamura S. 2008. Effects of endocrine disrupting chemicals on amphibian metamorphosis and mitochondrial membrane permeability transition. J. Health Sci. 54:273-280.

34. Nakagawa Y, Tayama S. 2000. Metabolism and cytotoxicity of bisphenol A and other bisphenols in isolated rat hepatocytes. Arch. Toxicol. 74:99-105.

35. Perkins GA, Scott R, Perez A, Ellisman MH, Johnson JE, Fox DA. 2012. Bcl-xL-mediated remodeling of rod and cone synaptic mitochondria after postnatal lead exposure: Electron microscopy, tomography and oxygen consumption. Molecular Vision. 18:3029-3048. 